\title{
益生菌、肠道菌群与健康
}

\author{
张和平
}

内蒙古农业大学食品科学与工程学院, 呼和浩特 010018

\section{Probiotics, gut microbes and health}

\section{Heping Zhang}

College of Food Science and Engineering, Inner Mogolia Agricultural University, Huhhot 010018, China doi: 10.1360/N972018-01074

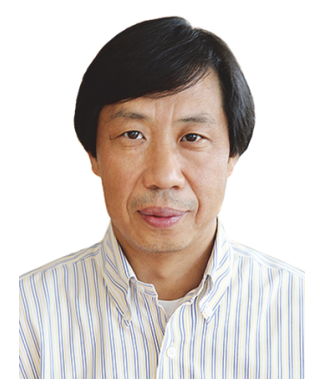

\section{强和平}

教授, 博士研究生导师, 乳 品生物技术与工程教育部重 点实验室、农业农村部奶制 品加工重点实验室、乳酸菌 䇻选与乳品发酵技术国家地 方联合工程实验室负责人。 2010 年获得国家杰出青年科 学基金; 2012 年入选“长江学 者” 奖励计划特聘教授; 2013 年入选“国家百千万人才工 程”、并获“有突出贡献中青年 专家”称号; 2015 年入选全国 农业科研杰出人才; 2016 年 入选国家“万人计划”科技创 新领军人才. 先后获“内蒙古 自治区科学技术特别贡献 奖”(2013 年)、“何梁何利科技 创新奖”(2015 年)、农业部 2017 年度 “神农中华农业科 技奖一一优秀创新团队奖”.
在过去的 15 年, 测序手段、生物信息学及宏基因组技术的快速发展, 使得探索肠道微 生物的组成和功能成为可能, 并由此涌现出一大批举世瞩目的研究成果. 目前, 肠道菌群 已发展成为生命科学、食品营养学、医疗保健和微生物学等众多领域的研究热点. 据报道, 2013 2017年, 专注于肠道微生物的论著多达 12900种, 仅 2017 年围绕肠道微生物就有4000 余篇学术论文发表. 该领域的蓬勃发展侧面反映了肠道菌群研究的重要性和必要性.

研究发现, 寄居在肠道中的多样性丰富且物种繁多的微生物是宿主代谢的重要参与者, 在宿主的食物消化和营养吸收、免疫调节、疾病防御等方面扮演着重要的角色. 通过调节肠 道菌群来预防和治疗一些疾病开始受到越来越多人的认可，甚至有人已经提出了“囷群疗 法”. 然而, 肠道菌群受多种因素的影响, 如饮食、地域、年龄、民族等均与肠道菌群组成密 切相关. 即便是同一个体的肠道菌群也很容易受到外界条件如饮食、作息、疾病状态、季节 变迁等的影响, 这些差异和变化告诉我们, 肠道菌群调控应该以个体为单位, 在充分了解宿 主肠道微生物组成特点的基础上开展肠道菌群个性化调控将是未来研究的重要方向之一.

益生菌被世界卫生组织定义为“活的微生物，当摄入足够量时能够对宿主身体健康产 生有益影响”。乳酸菌和双歧杆菌是益生菌菌株的重要来源, 众多分离株具有长期安全使用 的历史. 其中, 一些菌株作为调节肠道菌群平衡、影响脑健康和心理健康的天然制剂, 在医 疗保健和替代医学领域应用广泛. 全球范围内关于益生菌与肠道菌群的研究报道层出不穷, 然而, 这些研究大多集中在国外的一些益生菌菌株, 基于我国人群肠道菌群特点开发的益 生菌凤毛麟角. 同时, 益生菌与肠道菌群的互作机制研究仍然不够深入, 尚不清楚益生菌 如何作用于宿主肠道菌群, 进而缓解、改善某些疾病症状. 目前, 有关益生菌与肠道菌群的 认知只是冰山一角, 我们仍需继续努力, 任重道远.

我国幅员辽阔，民族众多，人口基数大，饮食文化差异极其显著，拥有高度复杂和丰 富的肠道菌群, 这为肠道微生物的研究提供了良好的样本来源. 近些年, 我国多个团队已 经致力于肠道菌群研究, 同时也致力于开发适合中国人群的益生菌, 并且取得了一系列的 创新性研究成果. 本专辑诚邀陈坚、杨瑞馥、陈卫、王硕、姚颖、张勇、孙志宏等十余位 国内知名学者就益生菌、肠道菌群与健康和疾病等研究领域的前沿成果进行了报道和评述. 内容涵盖了益生菌的开发和应用、益生菌研究的最新技术、益生菌对微量元素吸收、肠道 菌群的最新动态以及肠道菌群研究的标准化方法等. 同时关注了我国自主分离、笁选, 具有 完全知识产权的益生菌菌株的功能，以期使更多人了解我国益生菌与肠道菌群的研究现状. 期望本专辑的出版能够成为读者了解益生菌、肠道菌群及健康之间关系的窗口, 使更多年 轻的科研工作者了解、认识益生菌与肠道菌群, 加入肠道菌群的研究队伍, 同时对益生菌、 肠道菌群及健康的知识传播和益生菌领域的兴旺发展产生积极的推动作用.

谨以本专辑献给坚守在益生菌和肠道菌群研究领域的专家和学者. 衷心感谢各位专家 在百忙之中为本专辑撰稿, 是他们的辛勤付出和大力支持使本专辑得以出版! 